\title{
EFEITO DE EXTRATOS ORGÂNICOS DE MELIACEAE SOBRE BEMISIA TABACI (GENNADIUS) BIÓTIPO B EM TOMATEIRO
}

\author{
G.C.D. Bezerra-Silva ${ }^{1}$, J.D. Vendramim ${ }^{1}$, M.A. Silva ${ }^{1}$, C.T.S. Dias ${ }^{2}$ \\ ${ }^{1}$ Universidade de São Paulo, Escola Superior de Agricultura “Luiz de Queiroz", Departamento de Entomo- \\ logia e Acarologia, Av. Pádua Dias, 11, CEP 13418-900, Piracicaba, SP, Brasil. E-mail: gbezerra@esalq.usp.br
}

\section{RESUMO}

Avaliou-se o efeito de extratos orgânicos de Azadirachta indica, Melia azedarach, Toona ciliata e Trichilia pallida (Rutales: Meliaceae) sobre ovos e ninfas de Bemisia tabaci (Hemiptera: Aleyrodidae) biótipo B. Folhas e ramos foram secos, moídos e submetidos à extração (Soxhlet) em diclorometano e em etanol. Visando estabelecer uma concentração adequada para os estudos subsequentes, foram utilizados ovos oriundos de 40 adultos que foram mantidos por $24 \mathrm{~h}$ em folíolos de tomateiro em gaiolas de voil. Após 9 dias, contou-se o número de ninfas e pulverizou-se o extrato de folhas de T. pallida em diclorometano em diferentes concentrações $(0,32 ; 0,56 ; 1,0 ; 1,8$ e 3,2\%), além de água e acetona (controles). A mortalidade ninfal foi avaliada após sete dias. O experimento foi conduzido em delineamento inteiramente aleatorizado, com sete tratamentos e quatro repetições. Posteriormente, extratos em diclorometano e em etanol foram pulverizados sobre ovos na concentração selecionada (0,56\%), em experimentos distintos para cada solvente. Após nove dias, avaliou-se a mortalidade dos ovos e fez-se nova pulverização, avaliando-se, após sete dias, a mortalidade ninfal. Os experimentos foram conduzidos em delineamento com blocos aleatorizados (10 tratamentos e quatro repetições). Os dados foram submetidos à análise de regressão, análise de variância e comparados pelo teste de Tukey. Observou-se maior rendimento dos extratos em etanol em relação aos extratos em diclorometano. Os extratos em diclorometano de folhas e de ramos das meliáceas afetaram significativamente a sobrevivência de ovos e ninfas da mosca-branca. Os extratos em etanol afetaram a fase de ninfa, mas não apresentaram atividade ovicida.

PALAVRAS-CHAVE: Insecta, mosca-branca, aleloquímicos, limonoides.

\section{ABSTRACT}

EFFECTOFORGANICEXTRACTSFROMMELIACEAEON BEMISIA TABACI(GENNADIUS) B BIOTYPE IN TOMATO PLANTS. The effect of organic extracts from Azadirachta indica, Melia azedarach, Toona ciliata and Trichilia pallida (Rutales: Meliaceae) on eggs and nymphs of Bemisia tabaci (Hemiptera: Aleyrodidae) B biotype was assessed. Leaves and branches were dried, ground and submitted to extraction (Soxhlet) with dichloromethane and ethanol. To establish an adequate concentration for the subsequent tests, eggs were used originating from 40 adults maintained for $24 \mathrm{~h}$ on tomato leaves in voile cages. After 9 days, the number of nymphs was determined and the dichloromethane extract from T. pallida leaves was sprayed at different concentrations $(0.32,0.56,1.0$, 1.8 and $3.2 \%$ ); water and acetone were also used (controls). The nymphal mortality was evaluated after 7 days. An entirely randomized design was used, with 7 treatments and 4 replications. Afterwards, dichloromethane and ethanol extracts were sprayed on eggs at the selected concentration $(0.56 \%)$, in different experiments. After 9 days, the egg mortality was evaluated and a new spraying was conducted to assess the nymphal mortality after 7 days. These experiments were conducted in a randomized block designed (10 treatments and 4 replications). The data was submitted to regression analysis, analysis of variance and compared by the Tukey test. A higher yield was observed for the ethanol extracts in relation to the dichloromethane extracts. The dichloromethane extracts from leaves and branches from meliaceas significantly affected the survival of the whitefly eggs and nymphs. The ethanol extracts affected the nymphal phase, but did not present ovicidal activity.

KEY WORDS: Insecta, whitefly, allelochemicals, limonoids.

${ }^{2}$ Universidade de São Paulo, Escola Superior de Agricultura "Luiz de Queiroz", Departamento de Ciências Exatas, Piracicaba, SP, Brasil. 


\section{INTRODUÇÃO}

O tomate (Solanum lycopersicum L.) é considerado a mais importante hortaliça produzida no país, sendo utilizado na dieta alimentar como fonte de vitaminas e minerais. O Brasil produziu em 2009 cerca de 3,93 milhões de toneladas de tomate em uma área plantada de 61.658 hectares (FNP, 2010), sendo considerado, assim, um dos maiores produtores mundiais do produto. Como as demais lavouras plantadas em larga escala, o tomateiro é atacado por um grande número de artrópodes-praga e os danos causados por esses organismos são de tal magnitude que o tomateiro ocupa a posição de hortaliça líder no emprego de agrotóxicos. $\mathrm{O}$ atual sistema onera o custo de produção, favorece a seleção de pragas e patógenos resistentes aos produtos utilizados, provoca a eliminação de insetos benéficos (inimigos naturais e polinizadores), favorece a proliferação de pragas secundárias, causa impacto negativo no ambiente e coloca em risco a saúde de produtores e consumidores (VILlAs BôAs et al., 2007).

As pressões impostas pelos modernos agroecossistemas têm propiciado inclusive a mudança de status de pragas no ambiente agrícola e Bemisia tabaci (Gennadius) (Hemiptera: Aleyrodidae) é um exemplo típico desse fenômeno, já que nas três últimas décadas esse inseto passou de praga secundária a primária. Para entender tais mudanças, foram estudados os aspectos inter e intraespecíficos das populações de B. tabaci. Os resultados obtidos revelaram que havia populações apresentando grande variabilidade genotípica e fenotípica, originando, então, o complexo de raças (=biótipo) de B. tabaci (BROWn et al.,1995a; Perring, 2001). Entre os biótipos de B. tabaci, o mais agressivo é o " $\mathrm{B}$ ”, que geralmente predomina onde essa praga está presente, pois possui maior capacidade de dispersão e adaptação a novas plantas hospedeiras e a condições climáticas diversas, além disso, apresenta maiores taxas de oviposição quando comparado com outros biótipos e outras espécies de moscas-brancas (BROwn et al., 1995b). A mosca-branca B. tabaci biótipo B é uma das principais pragas tanto do tomateiro rasteiro (para processamento industrial) como do tomateiro estaqueado (tomate mesa) no Brasil (VIllas BôAs et al., 2007). O seu controle é de difícil execução, pois possui alta capacidade reprodutiva (LoURENÇão; NAGAI, 1994), atua como vetor de geminivírus, causando prejuízo em baixa densidade populacional (HiLjE, 2005) e também por apresentar resistência aos inseticidas convencionais com facilidade (PrabHaker et al., 1998).

Diversas técnicas de manejo têm sido alvo de estudos em nível mundial para o controle desse inseto, entre as quais se incluem o controle biológico (Wraight et al., 2000), a resistência de plantas
(FANCELli; VendRAMiM, 2002) e, mais recentemente, o uso de extratos botânicos com atividade inseticida (NARDo et al., 1997; SouZA; Vendramim, 2000a, 2000b, $2001,2004,2005)$, que eram mais utilizados no passado, antes do advento dos inseticidas sintéticos.

$\mathrm{O}$ uso de extratos vegetais pode ser uma ferramenta importante no manejo da mosca-branca, uma vez que podem controlar o inseto, reduzir ou eliminar o número de pulverizações com inseticidas sintéticos e, ainda, possibilitar a implementação de outras estratégias de manejo. Pesquisas têm demonstrado que, na família Meliaceae, além de Azadirachta indica A. Juss (COUdRIET et al., 1985), outras espécies possuem potencial inseticida para o controle de pragas do tomateiro, tais como Melia azedarach L. (BRunherotto; VendRAmim, 2001) e Trichilia pallida (Swartz) (Thomazini et al., 2000).

Embora existam investigações com meliáceas no controle de B. tabaci (ABOU-FAKHR HAMmAD et al., 2001), geralmente os trabalhos avaliam as plantas em experimentos isolados (ABOU-FAKHR HAMmad; McAuslane, 2006; Coudriet et al., 1985), dificultando a comparação das espécies e de suas estruturas e, além disso, na maioria dos casos, restringem-se ao uso de extratos aquosos. Recentemente, OIANO-NETO et al. (1995) demonstraram que Toona ciliata Roemer (Meliaceae: Swietenioideae) apresenta limonoides com estruturas similares aos encontrados em meliáceas da subfamília Melioideae, tais como A. indica, M. azedarache T.pallida. Contudo, pouca ou nenhuma informação existe em relação ao efeito de seus derivados sobre insetos. Nesse sentido, desenvolveu-se esse trabalho com objetivo de avaliar o efeito de extratos orgânicos de ramos e de folhas de quatro meliáceas (A. indica, M. azedarach, T. ciliata e T. pallida) sobre ovos e ninfas de Bemisia tabaci biótipo B.

\section{MATERIAL E MÉTODOS}

Obtenção e criação de manutenção de $B$. tabaci biótipo B: A população inicial de $B$. tabaci biótipo $B$ foi obtida de uma criação do Centro de Fitossanidade do Instituto Agronômico de Campinas e mantida em casa de vegetação (com aproximadamente 2,5 $\mathrm{m}^{2}$ ). Os insetos foram criados em plantas de soja cv. IAC-24. A cada 30 dias, novas plantas eram introduzidas, substituindo aquelas em que tinha ocorrido emergência de adultos.

Obtenção e manutenção de plantas de tomateiro: As plantas de tomateiro (cv. Santa Clara) foram cultivadas em estufa, a partir de semeadura em bandejas de isopor (128 células) com substrato PlantmaxHortaliças ${ }^{\circledR}$, sendoo transplante das mudas realizado em torno de 15 a 20 dias após a semeadura.

Obtenção de material vegetal e dos extratos orgânicos: Folhas e ramos de $A$. indica, $M$. azedarach, 
T. ciliata e T. pallida foram coletados no período de novembro de 2006 a fevereiro de 2007 no campus da ESALQ/USP, secos em estufa com circulação de ar (aproximadamente a $40^{\circ} \mathrm{C}$, por 48 a $72 \mathrm{~h}$ ), triturados em moinho de facas, obtendo-se, então, os pósvegetais que foram armazenados separadamente por espécie e por estrutura vegetal, em frascos hermeticamente fechados. Para a obtenção dos extratos, os pós-vegetais foram submetidos à extração com os solventes diclorometano e etanol em sistema de extração de Soxhlet. Na extração, uma amostra de cerca de $40 \mathrm{~g}$ de pó de cada espécie vegetal e estrutura foi colocada em um cartucho de papel filtro e cada cartucho foi distribuído em cada um dos seis extratores de Soxhlet com 300 e 200 mL de solvente, respectivamente, para folhas eramos, permanecendo cada amostra sob refluxo durante $16 \mathrm{~h}$ para folhas e 10h para ramos. O término da extração foi determinado pela mudança de coloração do solvente, ou seja, quando ele passava a apresentar tonalidadeincolor ao passar pela amostra. Esse procedimento foi repetido até completar a quantidade de massa total extraída paracada espécie de planta eestrutura. Emseguida, os extratos foram concentrados em evaporador rotativo a $40^{\circ} \mathrm{C}$, à pressão reduzida. Após esse processo, os extratos foram colocados em capela com fluxo de ar até a completa evaporação dos solventes e, com base na quantidade de extrato obtido, foram calculados os rendimentos de extração para cada parte da planta considerada, já que se partiu de uma quantidade conhecida de pó de cada espécie vegetal.

Determinação de uma concentração adequada para estudos subsequentes. Utilizando folhas de T. pallida em solvente diclorometano, planta cuja atividade sobre mosca-branca já havia sido referida (Souza; Vendramim, 2004), estabeleceu-se uma concentração para posterior comparação dos extratos orgânicos de ramos e das folhas de meliáceas. Para isso, foram utilizadas cinco concentrações espaçadas logaritmicamente $(0,32 ; 0,56 ; 1,0 ; 1,8$ e $3,2 \%)$ e os controles água destilada e acetona (devido os extratos orgânicos terem sido diluídos em acetona), e avaliada a mortalidade da fase de ninfa. Para obtenção dos ovos (que produziram as ninfas testadas), foi utilizada uma gaiola cilíndrica, com cerca de $15 \mathrm{~cm}$ (confeccionada com tecido de voil), a qual podia ser aberta e fechada por um barbante em ambas as extremidades envolvendo uma folha de cada planta de tomateiro. Foi mantida uma gaiola por planta, sendo liberados 40 adultos não sexados da mosca-branca por um período de $24 \mathrm{~h}$, para a oviposição. Após nove dias, quando a maioria das ninfas de 2-3 dias deidade já estava fixa, as plantas foram levadas da casa de vegetação para o laboratório e foi feita a contagem das ninfas na face abaxial dos folíolos, retirandose os ovos que não tinham propiciado eclosão de ninfas. No dia seguinte, os folíolos com cerca de 50 ninfas foram pulverizados com as concentrações do extrato e os dois controles, por meio de pistola tipo gravidade (Arprex ${ }^{\circledR}$, modelo 5, 20/30 lb/ pol ${ }^{2}$ com bico de $0,8 \mathrm{~mm}$ ) adaptada como miniatomizador, de modo a obter uma cobertura completa deles. Sete dias após o tratamento, foi avaliada a mortalidade ninfal. As ninfas mortas foram caracterizadas pelo tamanho reduzido (em relação ao controle) e formato elíptico semelhante ao de ninfas de primeiro ínstar conforme descrito por EICHELKRAUT; CARDONA (1989), como também pelo ressecamento do corpo do inseto. $\mathrm{O}$ experimento foi conduzido em delineamento inteiramente aleatorizado, com sete tratamentos e quatro repetições, onde cada repetição correspondeu a dois folíolos por planta.

Efeito de extratos vegetais de meliáceas sobre ovos e ninfas de B. tabaci biótipo B: Foram conduzidos dois experimentos, um para comparar os oito extratos em diclorometano [duas estruturas (folhas e ramos) versus quatro espécies de meliáceas] e outro para comparar os oito extratos em etanol. Para obtenção dos ovos, foi utilizada a mesma metodologia descrita anteriormente e, a seguir, foi feita a contagem dos ovos na face abaxial dos folíolos, sendo selecionados dois folíolos de cada planta com cerca de 50 ovos por folíolo. Estes foram pulverizados por meio de miniatomizador, com os extratos na concentração de $0,56 \%$ (concentração selecionada no ensaio anterior), e dois controles (água destilada e acetona). A pós nove dias, quando as ninfas apresentavam 2-3 dias de idade, foi avaliada a mortalidade da fase de ovo, contando-se o número de ninfas eclodidas e o número de ovos inviáveis no folíolo. No dia seguinte $\left(10^{\circ} \mathrm{dia}\right)$, foi realizada uma segunda pulverização sobre os folíolos contendo apenas ninfas. Após sete dias, foi avaliada a mortalidade das ninfas, com base no critério descrito no item anterior. Em ambos os experimentos (solventes diclorometano e etanol), adotou-se o delineamento em blocos aleatorizados, com 10 tratamentos, sendo quatro espécies de plantas inseticidas versus duas estruturas vegetais (folhas e ramos) e dois controles (água destilada e acetona), com quatro repetições, onde cada repetição correspondeu a dois folíolos por planta. Após a obtenção das porcentagens de mortalidade da fase de ovo no nono dia e a mortalidade das ninfas no $17^{\circ}$ dia, foi determinada a eficiência dos extratos pela fórmula de SCHNEIDER-Orelli (1947):

$$
\text { MC }(\%)=\left(\frac{\text { Mortal. }(\%) \text { em T -Mortal. }(\%) \text { em C }}{100-\text { Mortal. }(\%) \text { em C }}\right) * 100,
$$

onde: $\mathrm{MC}(\%)=$ mortalidade corrigida; $\mathrm{C}=$ mortalidade no controle e $T=$ mortalidade no tratamento. Para esse cálculo, foi utilizado como mortalidade no controle o maior valor entre as mortalidades constatadas nos controles água e acetona. 
Análise estatística: Os dados de concentraçãomortalidade foram submetidos à análise de regressão não linear e à regressão probítica pelo programa SAS 9.1 (SAS INSTITUTE, 2003) para estimativa de uma concentraçãoletal $50\left(\mathrm{CL}_{50}\right)$. Os dados de mortalidade de ovos e de ninfas nos experimentos subsequentes foram submetidos à análise de variância, sendo as médias comparadas pelo teste de Tukey. Os testes de Bartlett (BARTLETT, 1937) e Shapiro-Wilk (SHAPIRO; WILK, 1965) foram aplicados para avaliar as pressuposições de homocedasticidade de variâncias dos tratamentos e normalidade dos resíduos, respectivamente. $\mathrm{Na}$ ausência desses pressupostos, os dados foram transformados pelo Método Potência Ótima de Box-Cox (Box; Cox, 1964). Nesse estudo, as análises foram realizadas utilizando o programa SAS de computação estatística (SAS INSTITUTE, 2003).

\section{RESULTADOS E DISCUSSÃO}

Rendimento dos extratos de meliáceas: A obtenção dos extratos foi realizada uma única vez, não sendo possível realizar uma análise estatística dos dados. Apesar disso, os rendimentos dos extratos em solvente diclorometano de folhas e de ramos das quatro espécies de meliáceas apresentaram maior variação entre estruturas de uma mesma espécie do que entre as espécies (Tabela 1). Para os extratos de folhas em diclorometano, $M$. azedarach apresentou o menor rendimento $(4,70 \%)$ e T. pallida o maior $(8,12 \%)$. Considerando os extratos de ramos, os rendimentos obtidos para as quatro espécies vegetais foram muito próximos variando de 1,13 a 1,75\%. Em princípio, o rendimento superior do extrato de folhas pode ser vantajoso, principalmente quando utilizado em larga escala, uma vez que as folhas são mais abundantes e comprometem menos a sobrevivência e o desenvolvimento das plantas.

Na comparação do rendimento dos extratos etanólicos de folhas e de ramos dentro de cada espécie vegetal, constatou-se que a variação em $A$. indica e $T$. ciliata foi menor do que em $M$. azedarach e T. pallida (Tabela 1).

Diferentemente, CunHa (2004), trabalhando com espécies do mesmo gênero (Trichilia pallida

Tabela 1 - Rendimento na obtenção de extratos nos solventes diclorometano e etanol de folhas e ramos de quatro espécies de meliáceas.

\begin{tabular}{|c|c|c|c|c|c|}
\hline \multirow{2}{*}{ Espécie } & \multirow{2}{*}{ Solvente } & \multirow{2}{*}{ Estrutura } & \multirow{2}{*}{ Material vegetal (g) } & \multicolumn{2}{|c|}{ Rendimento $^{1}$} \\
\hline & & & & $(\mathrm{g})$ & $(\%)$ \\
\hline \multirow{4}{*}{ Azadirachta indica } & \multirow{2}{*}{ Diclorometano } & Folhas & 240 & 12,84 & 5,35 \\
\hline & & Ramos & 720 & 11,53 & 1,60 \\
\hline & \multirow{2}{*}{ Etanol } & Folhas & 200 & 27,41 & 13,70 \\
\hline & & Ramos & 150 & 20,88 & 13,92 \\
\hline \multirow{4}{*}{ Melia azedarach } & \multirow{2}{*}{ Diclorometano } & Folhas & 565 & 26,59 & 4,70 \\
\hline & & Ramos & 540 & 9,45 & 1,75 \\
\hline & \multirow{2}{*}{ Etanol } & Folhas & 200 & 39,58 & 19,79 \\
\hline & & Ramos & 200 & 18,24 & 9,12 \\
\hline \multirow{4}{*}{ Toona ciliata } & \multirow{2}{*}{ Diclorometano } & Folhas & 415 & 29,16 & 7,02 \\
\hline & & Ramos & 375 & 4,82 & 1,28 \\
\hline & \multirow{2}{*}{ Etanol } & Folhas & 200 & 36,30 & 18,15 \\
\hline & & Ramos & 119 & 21,45 & 18,02 \\
\hline \multirow{4}{*}{ Trichilia pallida } & \multirow{2}{*}{ Diclorometano } & Folhas & 860 & 69,82 & 8,12 \\
\hline & & Ramos & 698 & 7,89 & 1,13 \\
\hline & \multirow{2}{*}{ Etanol } & Folhas & 200 & 35,67 & 17,83 \\
\hline & & Ramos & 200 & 11,32 & 5,66 \\
\hline
\end{tabular}

${ }^{1}$ Obtido a partir da quantidade (g) de material vegetal moído 
e T. pallens), encontrou maior variação entre as duas espécies do que entre as estruturas da mesma espécie, o que, no entanto, foi obtido com o uso de extratos aquosos, o que deve ter influenciado na diferença de rendimento. O mesmo autor, trabalhando com extratos orgânicos, encontrou um rendimento de $1,67 \%$ para o extrato diclorometânico de folhas de $T$. pallida, resultado inferior ao encontrado nesse trabalho $(8,12 \%)$. Provavelmente, a diferença nos rendimentos foi consequência da metodologia de extração, uma vez que CuNHA (2004) fez extração por maceração e, nesse trabalho, utilizou-se o extrator de Soxhlet para obtenção dos extratos. GnOATTO et al. (2007), estudando dois métodos de extração (Soxhlet e decocção) de metilxantinas em erva-mate (Ilex paraguariensis), demonstraram que a metodologia de extração influencia diretamente no teor dos compostos presentes nos extratos.

Determinação de uma concentração adequada para estudos subsequentes: Pretendia-se estimar a $\mathrm{CL}_{50}$ do referido extrato, por meio da análise de Probit [PROC Probit (SAS, 2003)], porém, os dados não se adequaram ao modelo, por ter ocorrido um $\chi^{2}$ de Pearson significativo e elevada heterogeneidade dos dados.

Nas concentrações até 10.000 ppm (1\%) observouse uma correlação entre a concentração do extrato em diclorometano de folhas de T. pallida e a mortalidade de ninfas de B. tabaci biótipo B, ou seja, com aumento na concentração do extrato registrou-se aumento na mortalidade de ninfas; contudo, nas concentrações imediatamente superiores, a mortalidade das ninfas se estabilizou (Fig. 1).
Em consequência, resolveu-se adotar, entre as concentrações testadas, a que ocasionou mortalidade entre 50 e $60 \%$ para ser utilizada nos ensaios subsequentes. Dessa forma, a concentração do extrato de folhas de T. pallida em diclorometano selecionada foi de 0,56\% (5.600 ppm) (Fig. 1). A definição de uma concentração mediana possibilita a comparação das quatro espécies de meliáceas (duas estruturas versus dois solventes) ao invés de estudar plantas, estruturas ou solventes de extração de forma isolada como vem sendo realizado para estudos de meliáceas com moscas-brancas (ABOU-FAKHR HAMMAD; McAusLANE, 2006; COUDRIET et al., 1985).

A heterogeneidade obtida no presente trabalho pode ser reflexo de vários fatores, desde características inerentes ao inseto, tais como variabilidade genética numa mesma população até características intrínsecas da planta inseticida. Essas evidências corroboram informações de GALlo et al. (2002), que mencionam que, para o uso de inseticidas botânicos em larga escala, seria necessária a padronização da bioatividade destas, entre outras características. Essa heterogeneidade com o uso de extratos botânicos de meliáceas no controle de $B$. tabaci biótipo B não é uma novidade. Com relação a T. pallida, SouzA; VENDRAMIM (2000a), em dois experimentos com extratos aquosos de ramos a $2 \%$, constataram variabilidade de $11 \%$ quando comparados os valores de eficiência dos extratos para a mortalidade de ninfas da moscabranca em dois experimentos. Posteriormente, SouzA; VENDRAMIM (2001) registraram alta variabilidade quando avaliaram a atividade de extratos aquosos de $M$. azedarach sobre ovos de mosca-branca, sendo que os extratos de frutos verdes e de frutos maduros

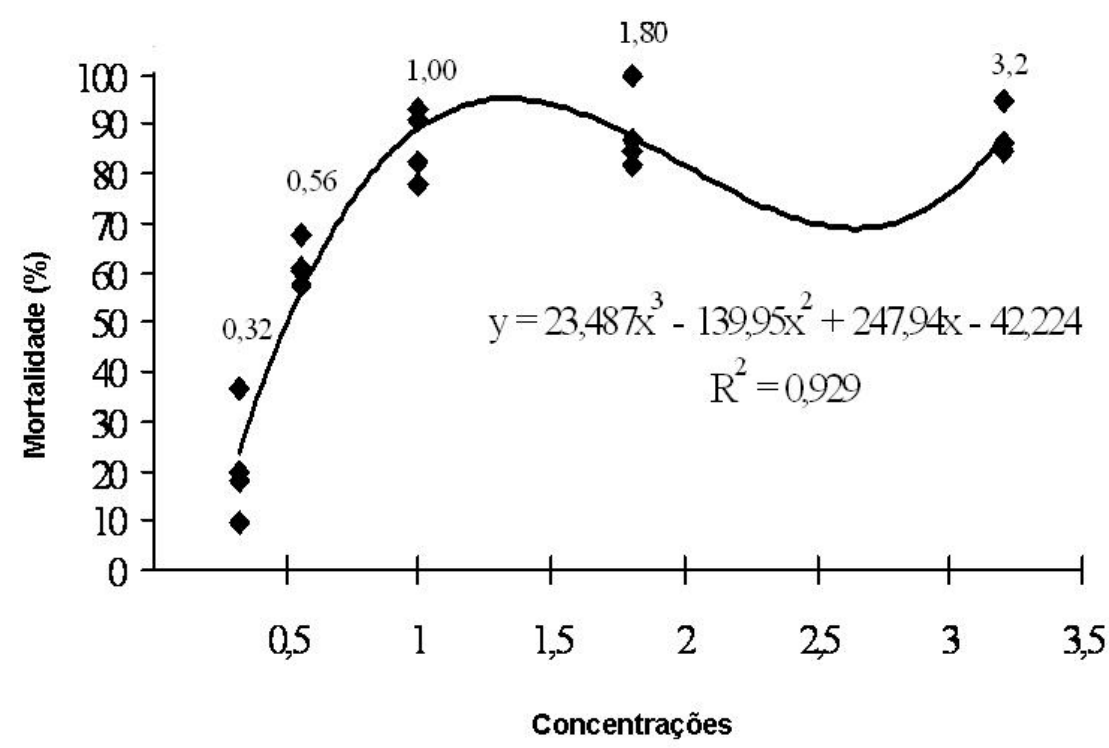

Fig. 1 - Concentração do extrato em diclorometano de folhas de Trichilia pallida e a mortalidade de ninfas de Bemisia tabaci biótipo B, em tomateiro, em casa de vegetação. Temp.: 24,26 \pm 5,42 ${ }^{\circ}$ C; UR: 70,05 $\pm 30,0 \%$; fotoperíodo natural. 
foram as estruturas da planta com a maior variação (26,9\% e $24,4 \%$ respectivamente).

Atividade comparada dos extratos orgânicos de ramos e de folhas de meliáceas: Os extratos em diclorometano causaram mortalidade de ovos, independentemente da espécie de meliácea e da estrutura da planta utilizada $(F=13,74 ; p<0,0001)$, porém não apresentaram diferenças entre si, diferindo apenas dos dois controles (água destilada e acetona) (Tabela 2).

No que se refere à mortalidade de ninfas, os extratos de ramos e de folhas de meliáceas em solvente diclorometano causaram alta mortalidade $(F$ $=40,01 ; p<0,0001) \mathrm{e}$, assim como aconteceu com a fase de ovo, os extratos não apresentaram diferenças entre si, diferindo apenas dos dois controles (água destilada e acetona) (Tabela 2).

Apesar denão ter sido feita comparaçãoestatística entre as mortalidades de ovos e ninfas, observa-se que os valores de mortalidade foram superiores em ninfas. Enquanto na fase de ovo o extrato com maior eficiência causou 23,44\% de mortalidade (ramos de M. azedarach), na fase de ninfa quase a totalidade dos insetos $(98,02 \%)$ foi controlada com o extrato de maior eficiência (ramos de T. ciliata). Provavelmente a maior mortalidade das ninfas seja devidoà ação residual dos extratos. Enquanto para a fase de ovo foi realizada apenas uma pulverização, para a fase de ninfa foram feitas duas pulverizações em sequência (após a obtenção dos ovos enove dias depois), o que provavelmente tenha aumentado a eficiência de controlenessa última fase. Os extratos de T. ciliata apresentaram maiores valores de eficiência, permitindo hipotetizar que os compostos presentes nos extratos dessa planta podem ter um período residual superior aos demais.

Os resultados de eficiência para ocontrole de ovos obtidos nesse ensaio, de forma geral, foram baixos. Comparando com a $\mathrm{DL}_{50}$ obtida por PRABHAKER et al. (1989) para extratos de sementes de nim, pode-se sugerir que a baixa eficiência possivelmente seja reflexo de uma baixa concentração (5.600 ppm) dos extratos utilizados. Outros trabalhos corroboram essa hipótese, como o de SouZA; Vendramim (2000a) que constataram eficiência no controle de ovos acima de $30 \%$ apenas para concentrações acima de 20.000 ppm utilizando extratos aquosos de folhas de $M$. azedarach e de ramos de T. pallida.

Comparando, por outro lado, as mortalidades causadas pelos extratos das duas estruturas (ramos e folhas), verifica-se que, com exceção da mortalidade de ovos com extratos de T. pallida e de A. indica (Tabela 2), nos demais casos há uma tendência de maior mortalidade com os extratos de ramos em relação aos extratos de folhas tanto para ninfas como para ovos, embora não tenha se constatado diferença estatística entre as médias.

Tabela 2 - Médias ( \pm EP) de mortalidade das fases de ovo e de ninfa de Bemisia tabaci biótipo B, em tomateiro, após aplicação de extratos (a 0,56\%) em diclorometano de diferentes estruturas vegetais e espécies de plantas da família Meliaceae em casa de vegetação. Temp.: 27,45 $\pm 3,64^{\circ} \mathrm{C}$; UR: $67,19 \pm 29,21 \%$; fotoperíodo natural.

\begin{tabular}{|c|c|c|c|c|c|}
\hline \multirow{2}{*}{ Extratos } & & \multicolumn{2}{|c|}{ Ovos } & \multicolumn{2}{|c|}{ Ninfas } \\
\hline & & Mortalidade ${ }^{*, 1}(\%)$ & Eficiência $^{2}(\%)$ & Mortalidade $^{*, 1}(\%)$ & \multirow[t]{2}{*}{ Eficiência $^{2}(\%)$} \\
\hline Água & & $0 \pm 0 \quad b$ & --- & $10,25 \pm 2,15 \quad b$ & \\
\hline Acetona & & $2,50 \pm 2,16 \quad b$ & --- & $1,46 \pm 0,85 \quad b$ & --- \\
\hline \multirow{2}{*}{ Trichilia pallida } & Folhas & $10,07 \pm 2,02 \mathrm{a}$ & 7,77 & $73,19 \pm 12,34 \mathrm{a}$ & 70,12 \\
\hline & Ramos & $7,74 \pm 1,51 \mathrm{a}$ & 5,38 & $91,31 \pm 2,08 \quad$ a & 90,31 \\
\hline \multirow{2}{*}{ Azadirachta indica } & Folhas & $16,93 \pm 5,61 \mathrm{a}$ & 14,80 & $67,79 \pm 9,00 \quad \mathrm{a}$ & 64,12 \\
\hline & Ramos & $16,87 \pm 4,68 \mathrm{a}$ & 14,74 & $72,34 \pm 5,15$ a & 69,18 \\
\hline \multirow{2}{*}{ Melia azedarach } & Folhas & $17,51 \pm 4,17 \mathrm{a}$ & 15,39 & $75,91 \pm 7,26$ a & 73,16 \\
\hline & Ramos & $25,35 \pm 5,56 \mathrm{a}$ & 23,44 & $88,18 \pm 3,59$ a & 86,83 \\
\hline \multirow{2}{*}{ Toona ciliata } & Folhas & $19,16 \pm 2,83 \mathrm{a}$ & 17,09 & $91,39 \pm 5,43$ a & 90,40 \\
\hline & Ramos & $21,64 \pm 6,30 \mathrm{a}$ & 19,63 & $98,22 \pm 0,90$ a & 98,02 \\
\hline $\mathrm{CV}(\%)$ & & 28,25 & & 3 & \\
\hline
\end{tabular}

*Médias seguidas de mesma letra, nas colunas, não diferem entre si pelo teste de Tukey ( $\mathrm{p}>0,05)$;

${ }^{1}$ Dados transformados pelo Método da Potência Ótima de Box-Cox com $\lambda=\log _{10}(X+0,5)$ (ovos) e $\lambda=\sqrt{x+0,5}$ (ninfas);

${ }^{2}$ Determinada pela fórmula de SchNEIDER-ORELli (1947). 
Tabela 3 - Médias ( \pm EP) de mortalidade das fases de ovo e de ninfa de B. tabaci biótipo B, em tomateiro, após aplicação de extratos (a 0,56\%) em etanol de diferentes estruturas vegetais e espécies de plantas da família meliácea em casa de

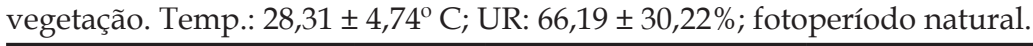

\begin{tabular}{|c|c|c|c|c|c|}
\hline \multirow{2}{*}{ Extratos } & & \multicolumn{2}{|c|}{ Ovos } & \multicolumn{2}{|c|}{ Ninfas } \\
\hline & & Mortalidade $^{* 1}(\%)$ & Eficiência $^{2}(\%)$ & Mortalidade*1 $(\%)$ & Eficiência $^{2}(\%)$ \\
\hline Água & & $12,47 \pm 5,61 \mathrm{abc}$ & -- & $11,41 \pm 0,73 \quad b$ & --- \\
\hline Acetona & & $2,19 \pm 0,76 \quad b c$ & --- & $24,08 \pm 5,01 \quad b$ & --- \\
\hline \multirow{2}{*}{ Trichilia pallida } & Folhas & $11,78 \pm 8,52 a b c$ & 0,00 & $86,96 \pm 6,08 \mathrm{a}$ & 82,82 \\
\hline & Ramos & $24,63 \pm 6,19 a b$ & 13,90 & $69,20 \pm 12,89 \mathrm{a}$ & 59,43 \\
\hline \multirow{2}{*}{ Azadirachta indica } & Folhas & $30,86 \pm 3,77 \mathrm{a}$ & 21,01 & $92,94 \pm 3,58 \mathrm{a}$ & 90,71 \\
\hline & Ramos & $0,90 \pm 0,65 \quad c$ & 0,00 & $95,45 \pm 1,78 a$ & 94,01 \\
\hline \multirow{2}{*}{ Melia azedarach } & Folhas & $28,26 \pm 1,78 \mathrm{a}$ & 18,04 & $82,64 \pm 11,01 \mathrm{a}$ & 77,13 \\
\hline & Ramos & $28,23 \pm 6,42 \mathrm{a}$ & 18,00 & $97,56 \pm 2,44 a$ & 96,79 \\
\hline \multirow{2}{*}{ Toona ciliata } & Folhas & $2,84 \pm 1,88 \quad c$ & 0,00 & $90,68 \pm 6,11 \mathrm{a}$ & 87,73 \\
\hline & Ramos & $3,03 \pm 1,32 \quad b c$ & 0,00 & $89,99 \pm 7,36 a$ & 86,82 \\
\hline $\mathrm{CV}(\%)$ & & 53,92 & & 18,58 & \\
\hline
\end{tabular}

A mortalidade de ovos nos tratamentos em que se utilizou o etanol como solvente variou de 0,90 a $30,86 \%$ (eficiências entre 0,00 e 21,01\%), enquanto nos controles, acetona e água, a mortalidade foi de 2,19 e $12,47 \%$, respectivamente. Os tratamentos apresentaram diferença significativa entre si ( $F=$ 6,36; $p<0,0001)$, sendo que os extratos de folhas de A. indica (30,86\%; eficiência de $21,01 \%)$ e de folhas e de ramos de $M$. azedarach (28,26 e 28,23\%, eficiências de 18,04 e 18,00\%, respectivamente) causaram maior mortalidade, diferindo dos constatados com os extratos de ramos de $A$. indica $(0,90 \%$; eficiência nula) e de folhas e de ramos de $T$. ciliata $(2,84$ e 3,03\%, também com eficiência nula nos dois casos) e do controle acetona $(2,19 \%)$, não diferindo, entretanto, dos demais tratamentos (extratos de folhas e de ramos de T. pallida) e do controle água (Tabela 3).

Em relação à mortalidade de ninfas, a variação foi de 69,20 a 97,56\% (eficiências variáveis de 59,43 a $96,79 \%$ ), enquanto nos controles as mortalidades foram de 11,41\% (água) e 24,08\% (acetona) $(F=15,29$; $p<0,0001$ ) (Tabela 3). Todos os tratamentos foram eficientes já que as mortalidades (variáveis de 69,20 a 97,56\%; eficiências variáveis de 59,43 e 96,79\%) foram superiores às registradas nos controles água $(11,41 \%)$ e acetona $(24,08 \%)$. Por outro lado, embora os referidos tratamentos com extratos não tenham diferido entre si, observa-se uma tendência de maior mortalidade causada por alguns dos tratamentos, principalmente aqueles em que foram empregados os extratos de ramos de $M$. azedarach $(97,56 \%$; eficiência de $96,79 \%$ ) e de ramos e de folhas de $A$. indica (95,45 e 92,94\%; eficiências de 94,01 e 90,71\%, respectivamente), em comparação ao valor obtido com o extrato de ramos de T. pallida $(69,20 \%$; eficiên- cia de 59,43\%) (Tabela 3). Observa-se que, mesmo não tendo sido feita comparação entre os valores de mortalidade de ovos e de ninfas, a mortalidade de ninfas foi superior à de ovos (Tabela 3).

PRABHAKER et al. (1989), trabalhando com cinco inseticidas e extratos de sementes de nim, constataram que, entre os estádios imaturos de B. tabaci, a fase de ovo é a mais difícil de ser controlada. Segundo esses autores, a $\mathrm{DL}_{50}$ deextratos de sementes de nim para a fase de ovo foi de 16.890 ppm, cerca de 12 vezes maior que a $\mathrm{DL}_{50}$ obtida com ninfas de primeiro ínstar (1.435 ppm), a fase mais suscetível do inseto. Ainda segundo esses autores, o ovoé mais difícil de ser afetado por estar protegido pelo córion, enquanto que a fase de "pupa" é menos sensível do que os primeiros ínstares ninfais devido ao seu maior tamanho, exigindo uma maior concentração dos inseticidas para alcançar efeito semelhante ao ocasionado em ninfas, ou ainda pela quantidade dos compostos inseticidas que realmente penetra o tegumento "pupal". Trabalhos como os de CouDRIET et al. (1985) e ABOU-FAKHR HAMMAD et al. (2000) também têm apontado que a fase de ninfa é a mais afetada pelos extratos botânicos. No que se refere ao nim, COUDRIET et al. (1985) sugerem que a maior sensibilidade que as ninfas de estádios iniciais apresentam se deva à ação dos derivados dessa planta no sistema neuro-endócrino que regula a produção de ecdisteroides ou pela sua ação como antiecdisteroides.

Oaltoíndice de mortalidade, provocado principalmente na fase de ninfa de $B$. tabaci biótipo B, sugere a presença de substâncias com atividade inseticida nos extratos orgânicos estudados nesse trabalho. Nesse sentido, é recomendável a identificação de frações 
com fontes de substâncias inseticidas dessas espécies e a realização de estudos subsequentes.

$O$ efeito de extratos de $T$. ciliata sobre $B$. tabaci biótipo B ainda não havia sido reportado no Brasil. O efeito de extratos dessa planta, contudo, já tinha sido avaliado sobre Spodoptera frugiperda (Lepidoptera: Noctuidae) por RodrigueZ; Vendramim (1997) que constataram que as lagartas alimentadas em dieta artificial contendo extratos de folhas alongaram o seu período de desenvolvimento e produziram pupas com menor peso. Utilizando extratos de caule de T. ciliata, entretanto, os referidos autores não registraram efeitos sobre $S$. frugiperda. Apesar dos resultados obtidos com essa espécie de planta, no presente estudo, não terem diferido dos demais tratamentos, os resultados são promissores.

\section{CONCLUSÕES}

1. Os extratos de folhas e de ramos das quatro espécies de meliáceas (A.indica, M. azedarach, T. ciliata e T. pallida) no solvente diclorometano apresentam baixa atividadeinseticida sobre ovos e alta em relação a ninfas de $B$. tabaci biótipo $B$.

2. Os extratos de folhas e de ramos dessas quatro espécies de meliáceas no solvente etanol não apresentam atividade inseticida sobre ovos, contudo, foi constatada alta atividade inseticida em relação a ninfas de $B$. tabaci biótipo B.

\section{REFERÊNCIAS}

ABOU-FAKHR HAMMAD, E.M.; NEMER, N.M.; HAWI, Z.K.; HANNA, L.T. Response of the sweetpotato whitefly, Bemisia tabaci, to the chinaberry tree (Melia azedarach L.) and its extracts. Annals of Applied Biology, v.137, n.2, p.79-88, 2000.

ABOU-FAKHR HAMMAD, E.M.; ZOURNAJIAN, H.; TALHOUK, S. Efficacy of extracts of Melia azedarach L. callus, leaves and fruits against adults of the sweetpotato whitefly Bemisia tabaci (Hom. Aleyrodidae). Journal of Applied Entomology, v. 125, p. 483-488, 2001.

ABOU-FAKHR HAMMAD, E.M.; McAUSLANE, H.J. Effect of Melia azedarach L. extract on Bemisia argentifolii (Hemiptera: Aleyrodidae) and its biocontrol agent Eretmocerus rui (Hymenoptera: Aphelinidae). Environmental Entomology, v. 35, n. 3, p.740-745, 2006.

BARTLETT, M.S. Properties of sufficiency and statistical tests. Proceedings of the Royal Society of London Series A, v.160, p. 268-282, 1937.

BOX, G.E.P.; COX, D.R. An analysis of transformations. Journal of the Royal Statistical Society, v.26, n.2, p.211-252, 1964.
BROWN, J.K.; COATS, S.; BEDFORD, I.D.; MARKHAM, P.G.; BIRD, J.; FROHLICH, D.R. Characterization and distribution of esterase electromorphs in the whitefly, Bemisia tabaci (Genn.) (Homoptera: Aleyrodidae). Biochemical Genetics, v.33, p.205-214, 1995a.

BROWN, J.K.; FROHLICH, D.R.; ROSSEL, R.C. The sweetpotato or silverleaf whiteflies: biotypes of Bemisia tabaci or a species complex? Annual Review of Entomolo$g y$, v.40, p.511-534, 1995b.

BRUNHEROTTO, R.; VENDRAMIM, J.D. Bioatividade de extratos aquosos de Melia azedarach L. sobre o desenvolvimento de Tuta absoluta (Meyrick) (Lepidoptera: Gelechiidae) em tomateiro. Neotropical Entomology, v.30, n.3, p.455-459, 2001.

COUDRIET, D.L.; PRABHAKER, N.; MEYERDIRK, D.E. Sweetpotato whitefly (Homoptera: Aleyrodidae): Effects of neem-seed extract on oviposition and immature stages. Environmental Entomology, v.14, n.6, p.776779, 1985.

CUNHA, U.S. da. Busca de substâncias de Trichilia pallida e Trichilia pallens (Meliaceae) com atividade sobre a traça-dotomateiro Tuta absoluta (Meyrick) (Lep.: Gelechiidae). 2004. 126f. Tese (Doutorado em Entomologia) - Escola Superior de Agricultura "Luiz de Queiroz", Universidade de São Paulo, Piracicaba, 2004.

EICHELKRAUT, K.; CARDONA, C. Biologia, cria massal y aspectos ecológicos de la mosca blanca Bemisia tabaci (Gennadius) (Homoptera; Aleyrodidae), com plaga del frijol comum. Turrialba, v.39, n.1, p.55-62, 1989.

FANCELLI, M.; VENDRAMIM, J.D. Development of Bemisia tabaci (Gennadius, 1889) biotype B on Lycopersicon spp. genotypes. Scientia Agricola, v.59, n.4, p.665669, 2002.

FNP. Tomate. AGRIANUAL: Anuário da Agricultura Brasileira. p.490-496, 2010.

GALLO, D.; NAKANO, O.; SILVEIRA NETO, S.; CARVALHO, R.P.L.; BAPTISTA, G.C. de; BERTI FILHO, E.; PARRA, J.R.P.; ZUCCHI, R.A.; ALVES, S.B.; VENDRAMIM, J.D.; MARCHINI, L.C.; LOPES, J.R.S.; OMOTO, C. (Ed.). Entomologia agrícola. Piracicaba: FEALQ, 2002. 920p.

GNOATTO, S.C.B.; BASSANI, V.L.; COELHO, G.C.; SCHENKEL, E.P. Influência do método de extração nos teores de metilxantinas em erva-mate (Ilex paraguariensis A. St.-Hil., Aquifoliaceae). Quimica Nova, v.30, n.2, p.304-307, 2007.

HILJE, L. Cómo determinar la repelência de substancias aleloquímicas sobre las moscas blancas. Manejo Integrado de Plagas y Agroecologia, n.74, p.94-98, 2005.

LOURENÇÃO, A.L.; NAGAI, H. Surtos populacionais de Bemisia tabaci no Estado de São Paulo. Bragantia, v.53, n.1, p.53-59. 1994. 
NARDO, E.A.B. de; COSTA, A.S.; LOURENÇÃO, A.L. Melia azedarach extract as antifeedant to Bemisia tabaci (Homoptera: Aleyrodidae). Florida Entomologist, v.80, n.1, p.92-94, 1997.

OIANO-NETO, J.; AGOSTINHO, S.M.M.; SILVA, M.F.G.F. da; VIEIRA, P.C.; FERNANDES, J.B.; PINHEIRO, A.L.; VILELA, E.F. Limonoids from seeds of Toona ciliata and their chemosystematic significance. Phytochemistry, v. 38, n. 2, p. 397-401, 1995.

PERRING, T.M. The Bemisia tabaci species complex. Crop Protection, v.20, p.725-737, 2001.

PRABHAKER, N.; TOSCANO, N.C.; COUDRIET, D.L. Susceptibility of the immature and adult stages of the sweetpotato whitefly (Homoptera: Aleyrodidae) to selected insecticides. Journal of Economic Entomology, v.82, n.4, p.983-988, 1989.

PRABHAKER, N.; TOSCANO, N.C.; HENNEBERRY, T.J. Evaluation of insecticide rotations and mixtures as resistance management strategies for Bemisia argentifolii (Homoptera: Aleyrodidae). Journal of Economic Entomology, v.91, n.4, p.820-826, 1998.

RODRIGUEZ, H.C.; VENDRAMIM, J.D. Avaliação da bioatividade de extratos aquosos de Meliaceae sobre Spodoptera frugiperda (J.E. Smith). Revista de Agricultura, v.72, n.3, p.305-318, 1997.

SAS INSTITUTE. SAS. STAT: users guide. Cary, NC, 2002-2003.

SCHNEIDER-ORELLI, O. Entomoligisches praktikum. Aarau: Sauerlander, 1947. 149p.

SHAPIRO, S.S.; WILK, M.B. An analysis of variance test for normality. Biometrika, v. 52, n.3/4, p. 591-611, 1965.

SOUZA, A.P.; VENDRAMIM, J.D. Atividade ovicida de extratos aquosos de meliáceas sobre a mosca-branca Bemisia tabaci (Gennadius, 1889) biótipo B em tomateiro. Scientia Agricola, v.57, p.403-406, 2000a.
SOUZA, A.P.; VENDRAMIM, J.D. Efeito de extratos aquosos de meliáceas sobre Bemisia tabaci biótipo B em tomateiro. Bragantia, v.59, p.173-179, 2000b.

SOUZA, A.P.; VENDRAMIM, J.D. Atividade inseticida de extratos aquosos de meliáceas sobre a moscabranca Bemisia tabaci (Genn.) biótipo B (Hemiptera: Aleyrodidae). Neotropical Entomology, v.30, p.133-137, 2001.

SOUZA, A.P.; VENDRAMIM, J.D. Bioatividade de extratos orgânicos e aquosos de meliáceas sobre Bemisia tabaci (Genn.) biótipo B em tomateiro. Arquivos do Instituto Biológico, São Paulo, v.71, n.4, p.493-497, 2004.

SOUZA, A.P.; VENDRAMIM, J.D. Efeito translaminar, sistêmico e de contato de extrato aquoso de sementes de nim sobre Bemisia tabaci (Genn.) biótipo B em tomateiro. Neotropical Entomology, v.34, n.1, p.83-87, 2005.

THOMAZINI, A.P.B.W.; VENDRAMIM, J.D.; LOPES, M.T.R. Extratos aquosos de Trichilia pallida e a traça-dotomateiro. Scientia Agricola, v.57, n.1, p.13-17, 2000.

VILLAS BÔAS, G.L.; MELO, P.E.; BRANCO, M.C.; GIORDANO, L.B.; MELO, W.F. Desenvolvimento de um modelo de produção integrada de tomate industria-PITI. In: ZAMBOLIM, L.; LOPES, C.A.; PICANÇO, M.C.; COSTA, H. (Ed.). Manejo integrado de doenças e pragas: hortaliças. Viçosa: UFV, 2007. cap. 9, p.349-362.

WRAIGHT, S.P.; CARRUTHERS, R.I.; JARONSKI, S.T.; BRADLEY, C.A.; GARZA, C.J.; GALAINI-WRAIGHT, S. Evaluation of the entomopathogenic fungi Beauveria bassiana and Paecilomyces fumosoroseus for microbial control of the silverleaf whitefly, Bemisia argentifollii. Biological Control, v.17, p.203-217, 2000.

Recebido em 31/3/09

Aceito em 3/8/10 